Lima, R.N.; Câmara, R.J.B.; Pãozinho, F.C. O geoturismo como segmento diferencial para o polo turístico da Chapada das Mesas: estudo de viabilidade de práticas geoturísticas no Complexo de Pedra Caída em Carolina (MA). Anais do IX Congresso Nacional de Ecoturismo e do V Encontro Interdisciplinar de Turismo em Unidades de Conservação. Revista Brasileira de Ecoturismo, São Paulo, v.6, n.4, nov-2013, pp.103-120.

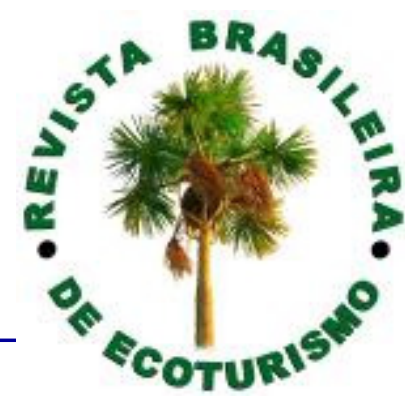

\title{
O geoturismo como segmento diferencial para o polo turístico da Chapada das Mesas: estudo de viabilidade de práticas geoturísticas no Complexo de Pedra Caída em Carolina (MA)
}

\author{
Geotourism as differential segment for the tourist pole of the Chapada das \\ Mesas: feasibility study of geotouristic practices in the 'Pedra Caída' Complex \\ in Carolina (MA, Brazil)
}

\section{Rozuila Neves Lima, Rosélis de Jesus Barbosa Câmara, Fernando Campelo Pãozinho}

\begin{abstract}
RESUMO
Diante dos segmentos do turismo surge algo inovador e que valoriza os aspectos geológicos e as formações do relevo em geral, unindo a contemplação dos monumentos naturais à busca de conhecimento. Esta forma de agregar valor turístico ao patrimônio geológico denominase Geoturismo. O real sentido da prática do geoturismo, compõe-se em atividades de educação, geoconservação e interpretação de geossítios, trabalhando roteiros guiados que instigue a conscientização de não degradar as formações e monumentos originários das ações do tempo e do relevo. Neste contexto,o objetivo geral da presente pesquisa é desenvolver um estudo acerca da viabilidade de desenvolvimento de práticas geoturísticas no entorno do Parque Nacional da Chapada das Mesas, mais especificamente no Complexo de Pedra Caída em Carolina - MA. Metodologicamente, esta é uma investigação exploratória e descritiva, que utiliza procedimentos bibliográficos, de campo e documental. O Parque Nacional da Chapada das Mesas foi o universo pesquisado, a amostra delimitou-se ao Complexo de Pedra Caída em Carolina-MA. Após aplicados os recursos sistemáticos da pesquisa, conclui-se que existe a viabilidade de práticas do geoturismo no Complexo de Pedra Caída.
\end{abstract}

PALAVRAS-CHAVE: Geoturismo; Geopatrimônio; Geoconservação; Parque Nacional da Chapada das Mesas.

\begin{abstract}
Given the segments of tourism is something innovative and that values the geological features and formations of the relief in general, combining the contemplation of the natural monuments to the pursuit of knowledge. This way of adding value to the tourist geopatrimônio called Geotourism. The real meaning of the practice of geotourism, consists of educational activities, and interpretation of geoconservation geosites working guided tours and instigate awareness of not degrading the originating formations and monuments of the actions of weather and topography. In this context, research the overall goal of this research is to develop a study on the feasibility of developing geoturísticas practices surrounding the National Park of Chapada das Mesas specifically in Complex Fallen Stone in Carolina - MA. It is methodologically of an exploratory and descriptive procedures using bibliographic and documentary field. The National Park of Chapada das Mesas was the universe surveyed, the sample was delimited to the Fallen Stone Complex in Carolina, MA. Given the methodology and results of the research concluded that the viability of geotourism practices in Complex Fallen Stone.
\end{abstract}

KEYWORDS: Geotourism; Geological Heritage; Geoconservation; National Park of Chapada das Mesas. 
O geoturismo como segmento diferencial para o polo turístico da Chapada das Mesas: estudo de viabilidade de práticas geoturísticas no Complexo de Pedra Caída em Carolina (MA)

\section{Introdução}

Da perspectiva de utilização do espaço geográfico para práticas turísticas surge a necessidade de se trabalhar a geoconservação, uma ferramenta de sensibilização e mobilização para proteger a geodiversidade, mais precisamente o geopatrimônio existente em um espaço ou região. Como consequência desta necessidade, originamse os geoparques, espaços com grande geodiversidade distribuídos em geossítios, em cuja área se pode desenvolver atividades voltadas para a visitação e educação geoambiental. Esta forma de agregar valor turístico ao geopatrimônio denomina-se Geoturismo. O real sentido da pratica do geoturismo, compõe-se em atividades de educação e interpretação de geossítios, trabalhando roteiros guiados de modo a instigar a conscientização a não degradar as formações e monumentos originários das ações do tempo e do relevo.

É nesse contexto que apresentamos um estudo acerca da viabilidade de práticas geoturísticas e sugestões de roteiros que considerem a geodiversidade do Complexo de Pedra Caída, localizado no entorno do Parque Nacional da Chapada das Mesas, em Carolina - MA, como segmento complementar à oferta turística existente. Assim vemos o geoturismo na condição de agente promotor da geoconservação a partir de estratégias de sensibilização e mobilização dos visitantes e moradores locais. . 1718-19 ...moradores locais. Através da transmissão de conhecimentos e de estímulos ao desenvolvimento de ações sustentáveis, quer-se utilizar os atrativos naturais para fins de lazer e turismo, direcionando tais princípios ao Complexo de Pedra Caída.

As propostas e discussões apresentadas resultam de estudos e pesquisas exploratórias e descritivas, desenvolvidas pelos grupo utilizando procedimentos bibliográficos, de campo e documental realizados pelos Grupos de Estudos e Pesquisas "Turismo e Meio Ambiente" e "Gestão, Marketing e Sustentabilidade no Turismo", com linha de pesquisa Desenvolvimento Regional e Marketing Territorial. A temática aqui abordada foi também objeto de produção monográfica.

\section{Geoturismo: ferramenta de geoconservação como segmento turístico}

O geoturismo é um segmento do turismo caracterizado por ter o patrimônio geológico como principal atrativo, e cuja sistemática de interpretação ambiental busca compreender os fenômenos geológico-geomorfológicos atuantes no local visitado, assim como promover as Ciências da Terra e o desenvolvimento sustentável das comunidades envolvidas. (LOPES; ARAÚJO, 2011, p.1). Este segmento trabalha questões voltadas para a geodiversidade e geoconservação trazendo como principais atrativos o geopatrimônio e atividades educativas, prática de lazer e recreação envolvendo as formações geomorfológicas (relevo, rochas, minerais, fósseis e solo) e geológicas (grutas, desfiladeiros e montanhas).

Um dos primeiros pesquisadores a trabalhar a questão da definição de Geoturismo foi Thomas Hose em 1990. É necessário estacar que antes dos estudos deste pesquisador, já se praticava o geoturismo, só que ainda sem denominações e características que o definissem, como afirma Lopes e Araújo (2011, p.2). 
A partir das concepções de Hose (1995 apud NASCIMENTO; RUCHKYS; MANTESSO-NETO, 2007, p.40), o geoturismo é a provisão de facilidades interpretativas e serviços para promover o valor e os benefícios sociais de lugares e materiais geológicos e geomorfológicos e assegurar sua conservação, para uso de estudantes, turistas e outras pessoas com interesse recreativo ou de lazer.

A ideia do geoturismo começou a se concretizar principalmente a partir da criação dos geoparques. O que pode se observar é que, com a valorização da geodiversidade por meio da geoconservação, gerou-se espaços voltados para a proteção e desenvolvimento de atividades de sensibilização, os geoparques. A partir deles percebeu-se que era possível realizar atividades turísticas com o objetivo de levar ao público noções de geoconservação, demonstrando como se modifica o ponto de vista do cidadão a partir do momento em que ele agrega valor a uma rocha, por exemplo. Seu olhar, então, se transforma, em busca de novas respostas para entender os processos que originaram o planeta - uma aula de evolução histórica capaz de instigar uma nova concepção acerca dos recursos naturais.

Alguns autores e pesquisadores consideram o geoturismo parte do ecoturismo, enquadrando-o como um subsegmento. Analisando tais afirmações, percebemos que as características de cada um dos dois segmentos possuem semelhanças, mas não devemos confundir seus objetivos e planos de estudo e foco. De modo geral, os atrativos geoturísticos são definidos como contrastes geológicos, falhas de relevo, montanhas, cachoeiras, vales, cavernas entres outros. Segundo Lopes e Araújo (2011, p.3),

O ecoturismo, assim como o geoturismo também envolve a sustentabilidade dos locais de visitação, porém, mesmo citando o patrimônio natural como parte dos atrativos, a geodiversidade não é contemplada, ficando apenas como um pano de fundo para a biodiversidade. Isto deixa claro que as atividades geoturísticas entram em ação para complementar a oferta em um espaço onde já exista a prática do ecoturismo, mas que não abrange a geodiversidade e a proteção do geopatrimônio.

Para explicar e diferenciar o geoturismo do ecoturismo, Silva (2008, p. 150) diz que:

[...] o patrimônio natural não envolve somente as formações biológicas, mas também as geológicas; porém, no ecoturismo, as formações geológicas não são tratadas com mesmo grau de profundidade, embora os aspectos associados ao meio abiótico, especialmente o relevo, também sejam atrativos importantes para o ecoturismo. Os maiores apelos a esse segmento são, sem dúvida, os atrativos relacionados ao meio biótico (fauna e flora). 
O geoturismo como segmento diferencial para o polo turístico da Chapada das Mesas: estudo de viabilidade de práticas geoturísticas no Complexo de Pedra Caída em Carolina (MA)

Em suma, o que deve ficar claro é que todos os segmentos do turismo ligados à natureza, promovendo práticas sustentáveis, estão intimamente ligados, não trabaIham de forma isolada, e em um mesmo espaço podem compartilhar atividades simultâneas, o que proporciona ao visitante uma percepção holística acerca da conservação dos espaços como ferramenta fundamental de sobrevivência dos próprios atrativos (Figura 4), recursos muitas vezes não renováveis. O objetivo comum entre tais segmentos pode ser descrito por Silva (2008):

Portanto, entende-se que o ecoturismo seria o segmento do turismo que trata mais especificamente do meio biótico (biodiversidade) como atração turística, enquanto o geoturismo teria o meio abiótico (geodiversidade) como principal atrativo. Deve-se lembrar, no entanto, que ambos os segmentos estão sempre se desenvolvendo, de forma a promover a proteção do patrimônio natural, histórico e cultural da região visitada. (SILVA, 2008, p. 150).

Ao analisar tais concepções, percebe-se a evolução das ideias de realização do turismo, atualmente, e se consegue englobar vários segmentos a partir de diversas atividades em um mesmo espaço ou território turístico. Os atrativos potenciais podem compartilhar novas experiências face aos novos modelos de abordagem de utilização dos equipamentos e serviços, visando a satisfação do visitante.

O geoturismo é estratégia de geoconservação, pois engloba também a preocupação com o desenvolvimento local, uma vez que, assim como qualquer outro segmento do turismo, ele gera indicadores econômicos para uma comunidade. Lopes e Araújo (2011) complementa que o geoturismo promove a geoconservação do patrimônio geológico e envolve as comunidades locais através das atividades econômicas sustentáveis, aumentando a oferta de emprego e renda e beneficiando o turista a partir da disponibilização de serviços, produtos e suprimentos.

Só em 2000, no Brasil, começou-se a promover tal segmento, em pequenos n [ucleos como o destacando Geoparque do Araripe no Estado do Ceará, o primeiro das Américas, e atividades geoturísticas nos Estados do Rio de Janeiro e Paraná por exemplo. De acordo com Silva (2008, p. 150),

No Brasil, uma das primeiras providências para se desenvolver o geoturismo é a identificação de aspectos geológicos que possam vir a se tornar atrativos turísticos. Sem dúvida, muitos exemplos de locais de interesse geoturístico já eram atrações, mesmo antes de os geocientistas os terem estudado. Alguns são verdadeiros cartões-postais do Brasil, que servem, inclusive, para identificar o país na atração de turistas do exterior, com destaque para Cataratas do Iguaçu, Pão de Açúcar e Lençóis Maranhenses. 
O geoturismo se apoia no tripé geodiversidade, patrimônio geológico e geoconservação. A essência do Geoturismo está na realização de atividades lúdicoeducativas que abordam conhecimentos básicos sobre o geopatrimônio, identificação dos geossítios, importância da conservação e do desenvolvimento sustentável da comunidade, importantes ferramentas para a geração de renda e a promoção do espaço como atrativo turístico.

\section{O Parque Nacional da Chapada das Mesas}

No Estado do Maranhão é possível observar a grande diversidade de biomas, distribuídos de forma a originar todo o complexo natural que se encontra nesta unidade federativa. De acordo com o Plano Maior, elaborado pelo Governo do Estado, os destinos turísticos no Maranhão se dividiram inicialmente em 5 (cinco) polos receptores principais: São Luís, Lençóis Maranhenses, Chapada das Mesas, Delta das Américas e Floresta dos Guarás. Esses polos agregam valores naturais e culturais, e instigam o trabalho compartilhado por meio de roteiros direcionados aos principais segmentos do turismo trabalhados em cada região.

A criação do Parque Nacional da Chapada das Mesas, em 12 de dezembro de 2005, classificado enquanto Unidade de Proteção Integral (nomenclatura segundo o Sistema Nacional de Unidades de Conservação), foi uma iniciativa federal, com o objetivo de minimizar os impactos ambientais que estavam sendo causados naquela região de cerrado, que abriga grande parte da fauna e flora nativa de vegetação tipo savana. De acordo com Galinkin et al. (2004 apud MORAES; LIMA, 2007, p.4057),

[...] a região Sul do Estado do Maranhão, onde se localiza a Chapada das Mesas, tem um valor considerável para a manutenção da biodiversidade brasileira, uma vez que atua como ecótono, área de transição ambiental, entre três biomas: Cerrado, Amazônia e Caatinga, portanto, com potencial para abrigar altos níveis de riqueza e abundância de espécies da flora e fauna.

O relevo da região é formado por 4 níveis de formação rochosa, e uma delas é a sambaíba, que forma morros e chapadas, de composição sedimentar e mais precisamente de arenito. As rochas possuem de 230 a 240 milhões de anos, originadas no período Triássico da Era Cenozoica. Outra característica das rochas da região é a presença de ferro e alumínio que formam a laterita, rocha escura que absorve calor.

Acredita-se que em períodos remotos da história do Planeta, essa região, onde hoje é o Parque Nacional da Chapada das Mesas, já foi fundo de mar. Ao longo das eras, as ações eólica e pluvial causaram um processo de erosão, dando origem aos cannyons. Nesta proposta de estudo, destaca-se como segmento diferencial para desenvolvimento do turismo e reconhecimento do valor da geodiversidade presente no Parque Nacional da Chapada das Mesas, o geoturismo. Iniciativa surgida da consciência hodiema em relação ao planeta, ele é capaz de diferenciar o produto turístico 
O geoturismo como segmento diferencial para o polo turístico da Chapada das Mesas: estudo de viabilidade de práticas geoturísticas no Complexo de Pedra Caída em Carolina (MA)

pelo ponto de vista econômico, agregar valores sustentáveis aos geossítios e incentivar as práticas de ações interpretativas e de educação geoambiental. O geoturismo se baseia na gestão de ideias compartilhadas, por meio de roteiros geoturísticos com foco na geoconservação, educação e práticas de esporte e lazer aos turistas. Dentre as Unidades de Conservação existentes no Maranhão, destaca-se neste estudo o Parque Nacional da Chapada das Mesas, localizado na região sudoeste do Maranhão (Figura 1).

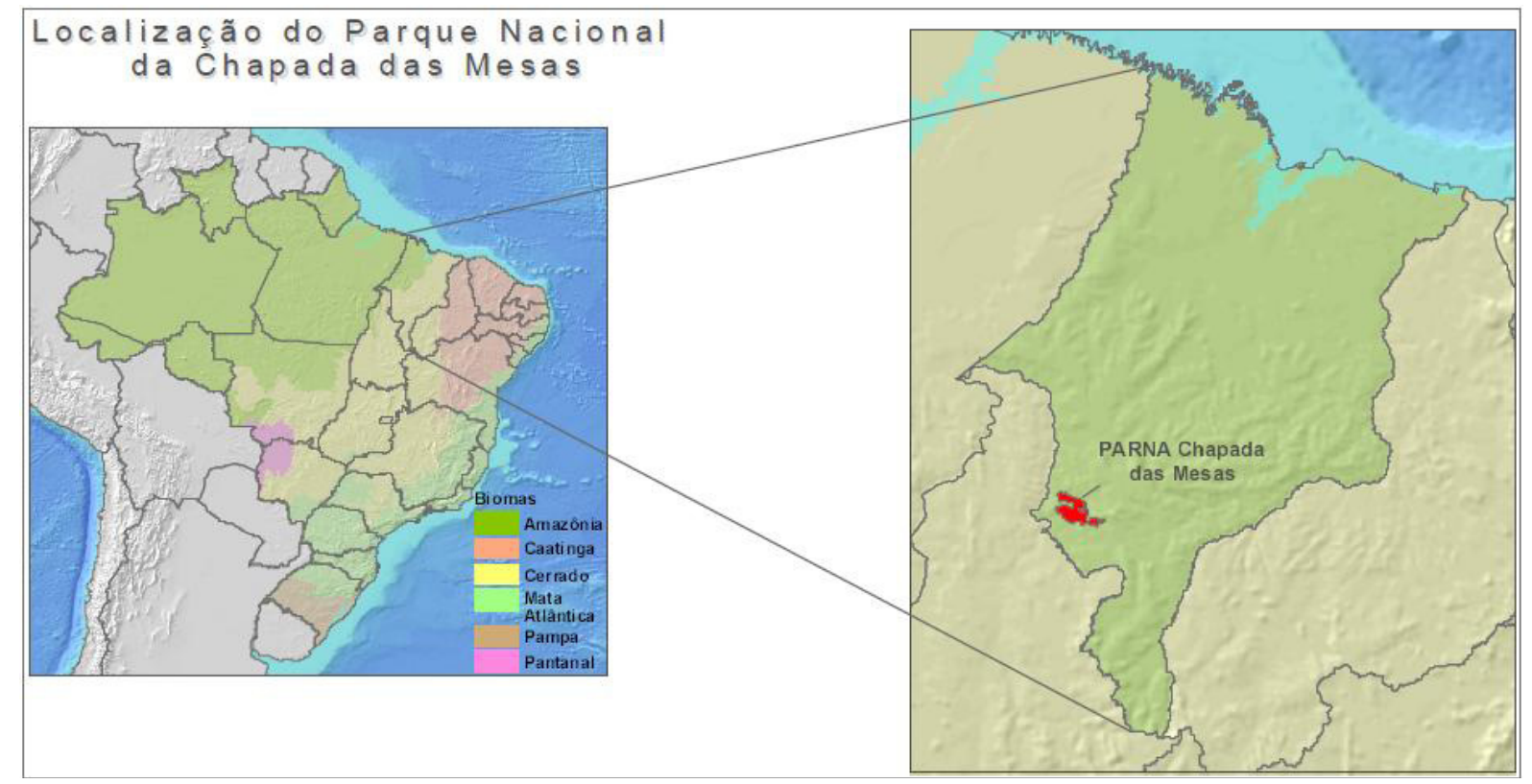

Figura 1: Mapa com a localização do Parque Nacional da Chapada das Mesas.

Figure 1: Map showing the location of the National Park of Chapada das Mesas.

Fonte: Brasil $(2007$, p.3).

Source: Brasil (2007, p.3).

No Estado do Maranhão, o geoturismo ainda não é explorado como um segmento mercadológico, o que justifica a relevância deste trabalho, ao propor sugestões de roteiro a partir do geoturismo no Complexo de Pedra Caída, sítio localizado na Zona de Amortecimento no Parque Nacional da Chapada das Mesas.

\section{Conhecendo o Complexo de Pedra Caída}

O Complexo de Pedra Caída localiza-se a aproximadamente $32 \mathrm{~km}$ da cidade de Carolina (MA) às margens da rodovia BR 230, trecho que liga os municípios de Carolina e Estreito, ambos na região sudoeste do Maranhão e está aproximadamente a $865 \mathrm{~km}$ da capital do Estado, São Luís. O Complexo apresenta uma estrutura turística dotada de equipamentos e serviços agregados aos diversos atrativos naturais, distribuídos em uma área total de 10.600 hectares de terra (Figura 2). 


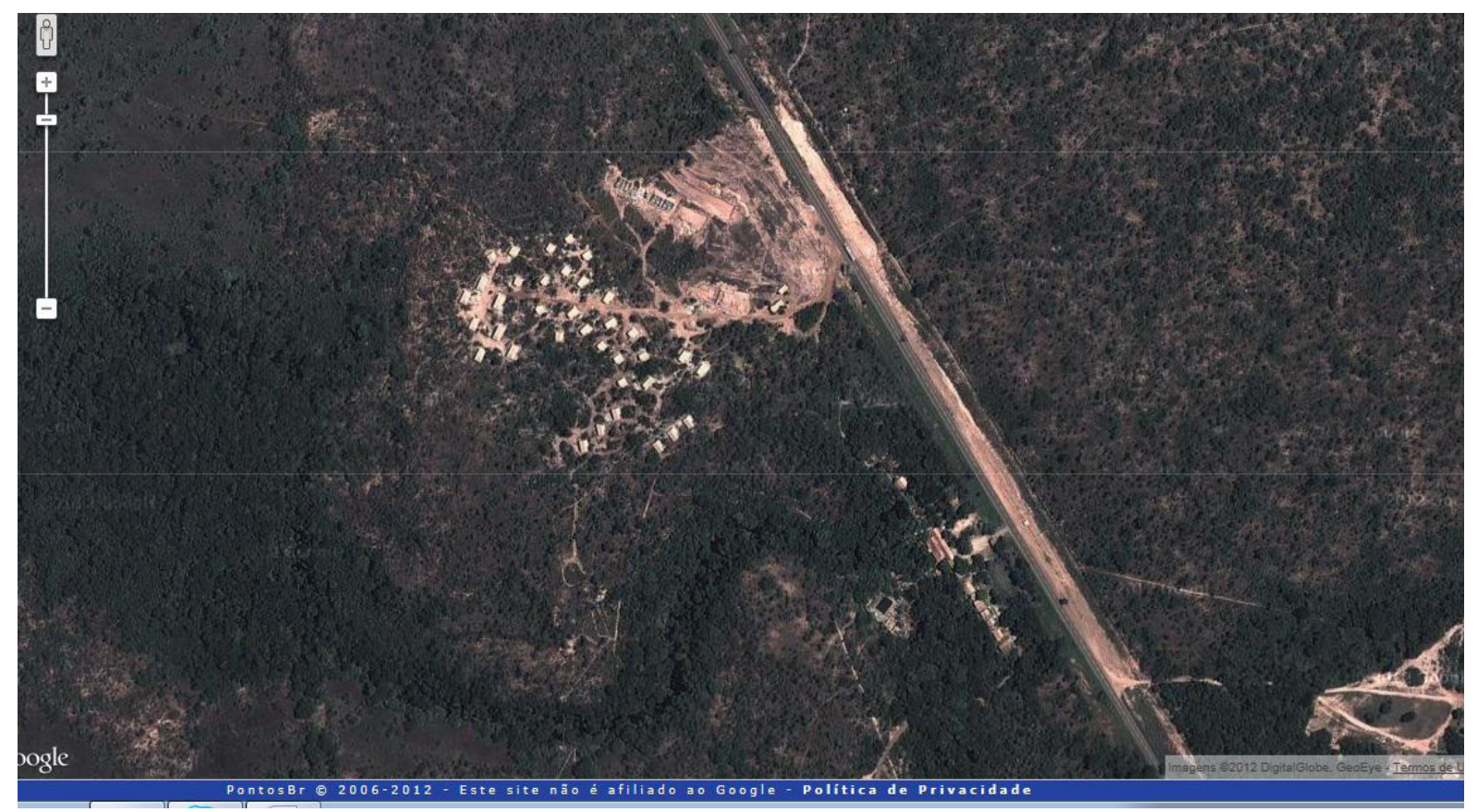

Figura 2: Visão aérea do Complexo de Pedra Vaída.

Figure 2: Aerial view of the Complex of Pedra Caída.

Fonte: Google Mapas. (Em: 16 de jul. 2012.).

Source: Google Maps. (On: 16 July 2012.).

O Complexo de Pedra Caída é uma área particular com forte interesse turístico, possui uma vasta diversidade geopatrimonial e utiliza o turismo como ferramenta de sensibilização e mobilização dos visitantes e comunidade residente em suas proximidades. O complexo já oferece as atrações naturais aos visitantes desde 1986. Em 2006 o atual proprietário, Pedro Iran Pereira do Espírito Santo, o Pipes, comprou o complexo, imprimiu sensíveis melhorias e expandiu a estrutura física de todo o espaço turístico de Pedra Caída, tornando-se um modelo empreendedor de gestão de equipamentos turísticos da região do Polo turístico da Chapada das Mesas.

Hoje, o Complexo de Pedra Caída é uma referência de práticas de turismo, pois dispõe de uma variedade de atrativos naturais como cachoeiras, cavernas, cannyons, piscinas naturais adaptadas, morros propícios para realização de atividades ligadas ao ecoturismo, como trilhas, contemplação da fauna e flora, cachoeiras e experiências voltadas ao turismo de aventura, como realização de trekking, rapel, tirolesa, arvorismo e escalada. O que se pode perceber é que todos estes segmentos estão atrelados a uma superfície espacial visível de geodiversidade. As características de vegetação tipo cerrado denota diversidade de geossítios, incluindo monumentos naturais formados por agentes internos e externos do relevo, como erosão eólica ou pluvial, agregados a certo valor notável para apreciação e estudo.

Diante destas características singulares, o Complexo de Pedra Caída está organizado estruturalmente com espaços de apoio ao visitante, em uma área receptiva. 
O geoturismo como segmento diferencial para o polo turístico da Chapada das Mesas: estudo de viabilidade de práticas geoturísticas no Complexo de Pedra Caída em Carolina (MA)

Nas demais áreas estão dispostos os principais atrativos e seus valores agregados para a realização do turismo com vista a práticas de conservação. Em sua estrutura física, o sítio dispõe de portão de entrada, salão de recepção, espaço de hospedagem, área de lazer, restauração, banheiros e estacionamento. Além dessa estrutura, destacam-se abaixo os principais geossítios de grande interesse e valor geoturístico:

Geossítio Santuário de Pedra: Distante 900 metros e tem como valor de interesse o conhecimento da formação rochosa, lazer e contemplação (Figura 3). O acesso é feito por trilha suspensa por meio de passarelas de madeira, e em algumas etapas do trajeto encontram-se rampas. Durante o percurso de 2 horas, pode-se perceber a variação da mudança de clima seco para úmido quando da aproximação do Santuário de Pedra Caída, uma caverna com uma fenda em sua parte superior de onde se forma a cachoeira com queda média de 50 metros.

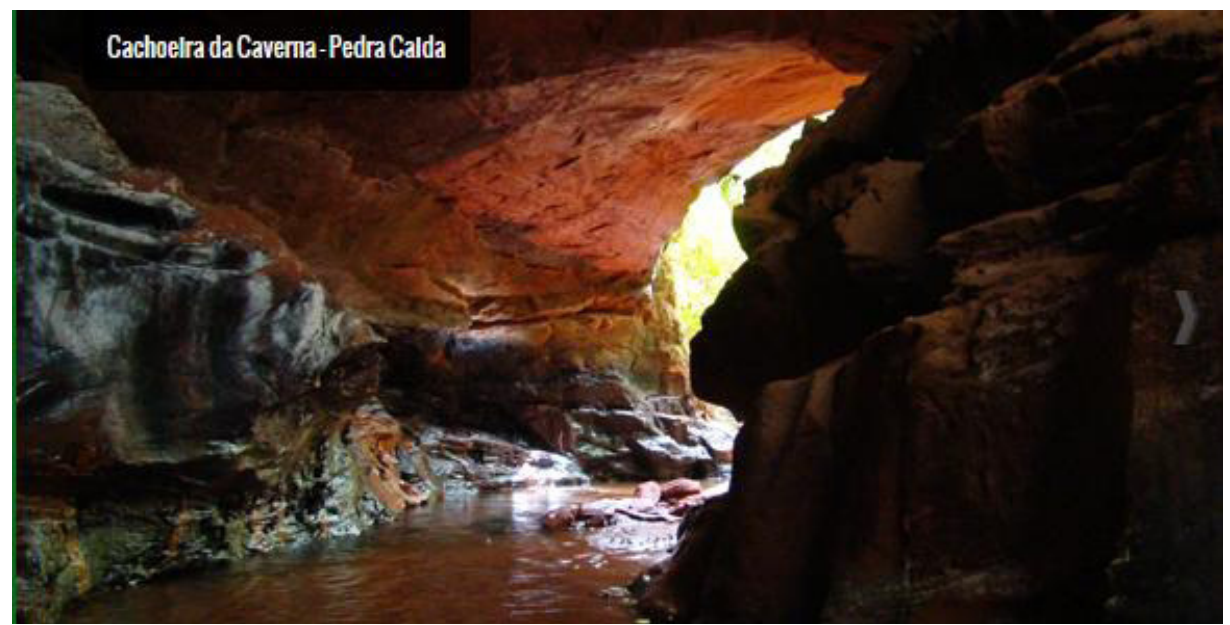

Figura 3: Cachoeira da Caverna. Figure 3: Cachoeira da Caverna. Fonte: Pedra Caída (2012). Source: Pedra Caída (2012).

Ao longo do trajeto (Figura 4) pode-se observar paredões rochosos e pedras diversas com características arenosas de fácil desgaste, a depender do agente causador.

Geossítio Cachoeira da Caverna e Capelão: Distante 6 km (Figura 5). Tem como valor de interesse o conhecimento sobre cavernas, aventura, lazer e recreação. $O$ percurso de $3 \mathrm{~h}$ e meia é realizado com transporte tipo tração, próprio para o tipo de terreno. Neste roteiro a paisagem é o elemento diferencial em um percurso em trilha de um nível leve, com mata do tipo ciliar. O ponto de maior interesse é uma caverna com uma fenda que vai de encontro a uma cachoeira que forma um poço de águas claras. A caverna torna-se um dos diferenciais deste roteiro e pode ser trabalhada sob perspectiva mais geológica. 


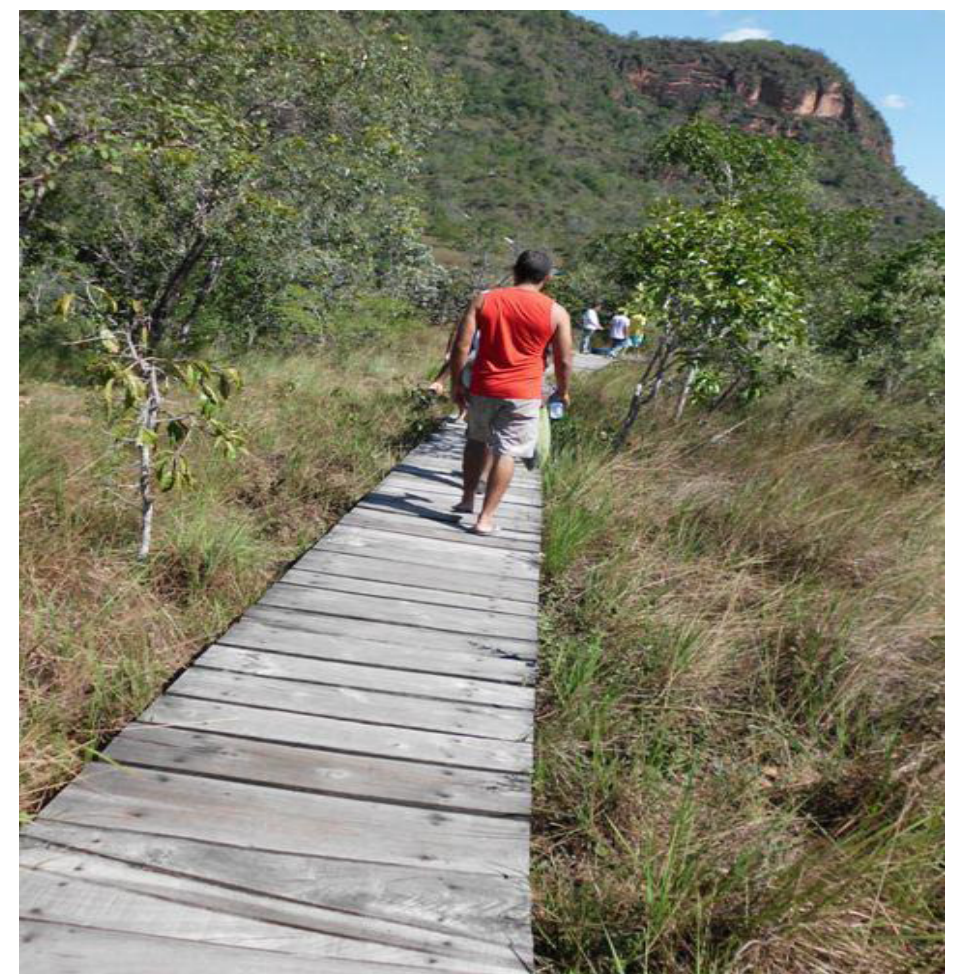

Figura 4: Percurso em trilhas até o Santuário de Pedra Caída. Figure 4: trek to the Sanctuary of Pedra Caída.

Fonte: Fernando Pãozinho (Em 5 de maio de 2012).

Source: Fernando Pãozinho (On May 5, 2012).

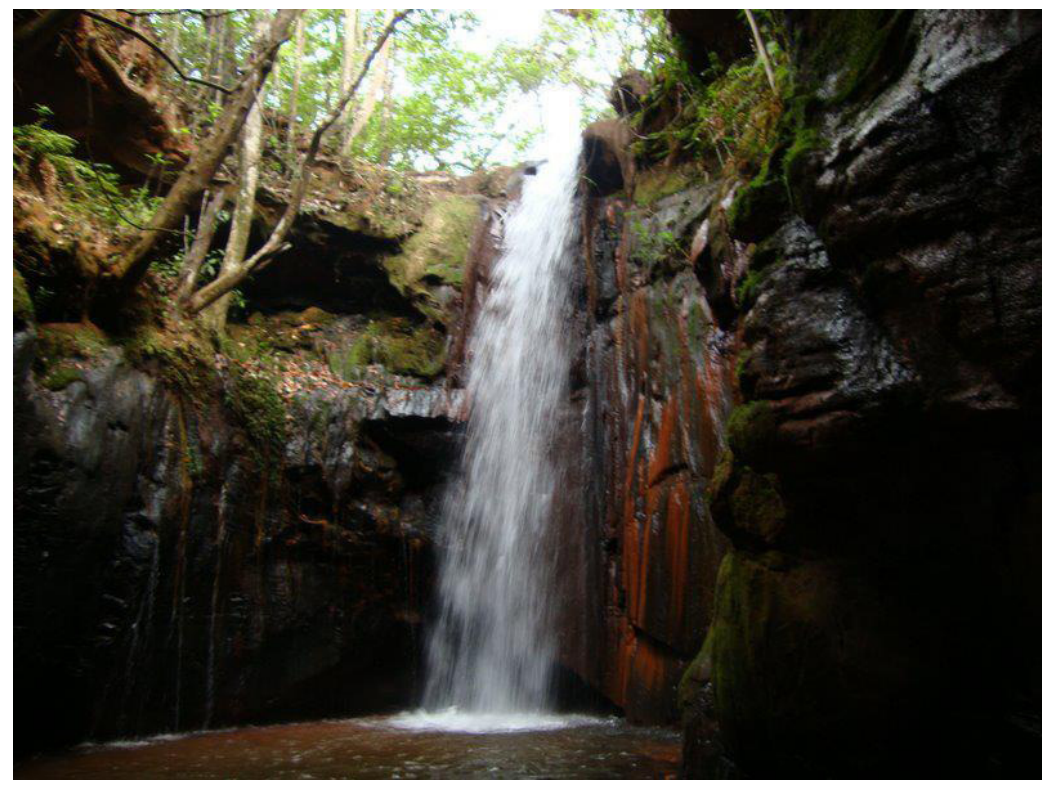

Figura 5: Cachoeira da Caverna. Figure 5: Cachoeira da Caverna.

Fonte: Fernando Pãozinho. (Em 5 de maio de 2012). Source: Fernando Pãozinho (On May 5, 2012). 
O geoturismo como segmento diferencial para o polo turístico da Chapada das Mesas: estudo de viabilidade de práticas geoturísticas no Complexo de Pedra Caída em Carolina (MA)

Geossítio Cachoeira da Pedra Furada: Distante $5 \mathrm{~km}$, tem como valor de interesse aventura, contemplação e lazer. O percurso de 3 horas é feito por meio de trekking (caminhada). O percurso à Cachoeira de Pedra Furada não indicado a idosos e crianças, pelo nível de dificuldade. A trilha leva a uma variedade de cenários envolvendo morros, chapadões e rio.

Geossítio Cachoeira Garrote e Porteira: Distante $9 \mathrm{~km}$, tem como valor de interesse a aventura, a contemplação e o lazer. O deslocamento até a Cachoeira do Garrote, em veículo off-road, é de 6 quilômetros e de lá à Cachoeira Porteira é de 3 quilômetros, perfazendo, no total, 3 horas de percurso. As características da geodiversidade presente no percurso compreendem formações de rochas arenosas e sedimentares, assim como os outros geossítios. Roteiro indicado para idosos e crianças pelo seu fácil acesso.

Geossítio Brilho: Distante 3,5 km e tem como valor de interesse aventura, contemplação e lazer. O percurso, de 2 horas, compreende 2 quilômetros de caminhada, tendo como referencial a sede do Complexo de Pedra Caída, em área de cerrado e 1 quilômetro através de hidro trekking (caminhada pelo curso d'água) até a Cachoeira. A Cachoeira Brilho fica próxima de outro ponto de interesse, a Cachoeira da Lua. Esta queda d'água localiza-se a aproximadamente 3 quilômetros de percurso. A beleza do ambiente é o forte atrativo deste geossítio, propício para atividades de lazer.

Devido às suas características geológicas, tais peculiaridades garantem aos geossítios seu valor geoturístico, permitindo, assim, desenvolver em cada ponto atividades dinâmicas, como painéis interpretativos para a apreciação do público observador. Percebe-se que são as cachoeiras os principais atrativos. Além dos pontos de interesse já mencionados anteriormente, as modificações do relevo local permitem a realização de práticas de esporte de aventura, agregando, assim, valor turístico à geodiversidade. As atividades de rappel, tirolesa, arvorismo, trilha e travessia da ponte pênsil permitem que o visitante contemple os diversos cenários naturais, e, em especial, o cannyon próximo ao Santuário de Pedras Caída. Desta forma, deve-se proporcionar ao público potencial inovações a partir de criação de novos pontos de interesse envolvendo monumentos naturais de grande notoriedade, destacando no percurso áreas que possam surpreender a percepção do público.O trabalho inteligente em torno da geodiversidade aguça a sensibilidade dos visitantes, e lhes propõe novos sentidos sobre o Complexo de Pedra Caída.

Nos percursos guiados, os monitores ambientais preocupam-se em transmitir informações sobre educação ambiental, conhecimentos sobre tipos de rocha, história geológica dos pontos de interesse. De maneira a controlar e preservar os recursos deste manancial, permite-se apenas de 15 a 20 pessoas por passeio, considerandose a capacidade de carga das trilhas e dos geossítios. Isso demonstra que no Complexo de Pedra Caída as atividades desenvolvidas já tendem ao geoturismo. Apenas não contam com instrumentos de divulgação e de classificação concreta acerca de tal segmento, de modo que as atividades não são baseadas em parâmetros e índices de 
desenvolvimentos a nível nacional ou internacional. Por ser um segmento novo no turismo, em termos de classificação de modalidade, o geoturismo ainda se mistura e é confundido com outros segmentos.

\section{Diagnóstico do complexo de Pedra Caída}

A segmentação deste tipo de mercado depende da posição obtida pela promoção desse tipo de turismo, uma vez que o proprietário do Complexo ainda não investiu estrategicamente na elaboração de roteiros formatados com as características do geoturismo. Para se desenvolver o geoturismo nas dependências do Complexo de Pedra Caída é necessário realizar um planejamento estratégico para direcionar as principais ações e aliar a uma nova construção de imagem, demonstrando potencialidades da geodiversidade para atrair públicos. Aí entram as motivações científicas, a educação geo-ambiental, que são produtos geoturísticos diferenciados. Esta é uma estratégia que fortalece a prática do ecoturismo e do turismo de aventura, influenciando na imagem do destino, principalmente se a proposta de implantação atingir níveis positivos como na criação de um geoparque que, por sua vez, pode ser credenciado em uma rede internacional. Essa estratégia contribui, sobretudo, para o ordenamento territorial e o desenvolvimento sustentável do Polo Turístico da Chapada das Mesas, assim tratado face ao mercado turístico do Estado do Maranhão.

Uma das mais relevantes vantagens do geoturismo é a possibilidade de ser desenvolvido no interior dos geoparques, e isto o diferencia pelos padrões de rede internacional conferindo ao visitante atividades geoturísticas reforçadas pelos modelos da UNESCO. De modo geral, os atrativos geoturísticos são definidos como contrastes geológicos, falhas de relevo, montanhas, cachoeiras, vales, cavernas entres outros. Outro aspecto relevante está no fato de que os agentes deste processo devem ser beneficiados com a geração de empregos, participação econômica nos espaços geoturísticos. Além disso, e principalmente, faz com que a própria comunidade agregue valor à geodiversidade para a conservação e proteção de territórios que fazem parte de sua identidade. É importante conhecer as condições atuais do Complexo de Pedra Caída para se perceber a viabilidade de práticas geoturísticas

Os aspectos positivos do Complexo são as estruturas, os equipamentos e os serviços diferenciados dos demais empreendimentos do Polo Turístico Chapada das Mesas, pois possui roteiros diferenciados, assim como diversas características que evidenciam a geodiversidade da região. Todos os condutores ambientais apresentam bom nível de conhecimento acerca dos atrativos turísticos existentes. e têm noção mínima sobre o que significa o geoturismo. Outro aspecto importante é a inserção da comunidade, pois todos os colaboradores, incluindo os condutores ambientais, moram na região, e isso abre grande vantagem, porque sua identidade está presente nos conhecimentos repassados aos visitantes e no domínio das informações também absorvidas acerca da preservação do seu próprio patrimônio natural.

Compondo o cenário negativo estão as dificuldades na comunicação com o Complexo de Pedra Caída para compra antecipada dos serviços e para obter informa- 
O geoturismo como segmento diferencial para o polo turístico da Chapada das Mesas: estudo de viabilidade de práticas geoturísticas no Complexo de Pedra Caída em Carolina (MA)

ções, assim como dificuldade na logística de transporte/modalidade de acesso dos visitantes que se hospedam em Carolina. Outro aspecto negativo consiste nas constantes ameaças de degradação da geodiversidade, pois muitas das rochas são riscadas por vândalos, modificando as rochas, fazendo assim avançar o processo de erosão das rochas (Figura 6).

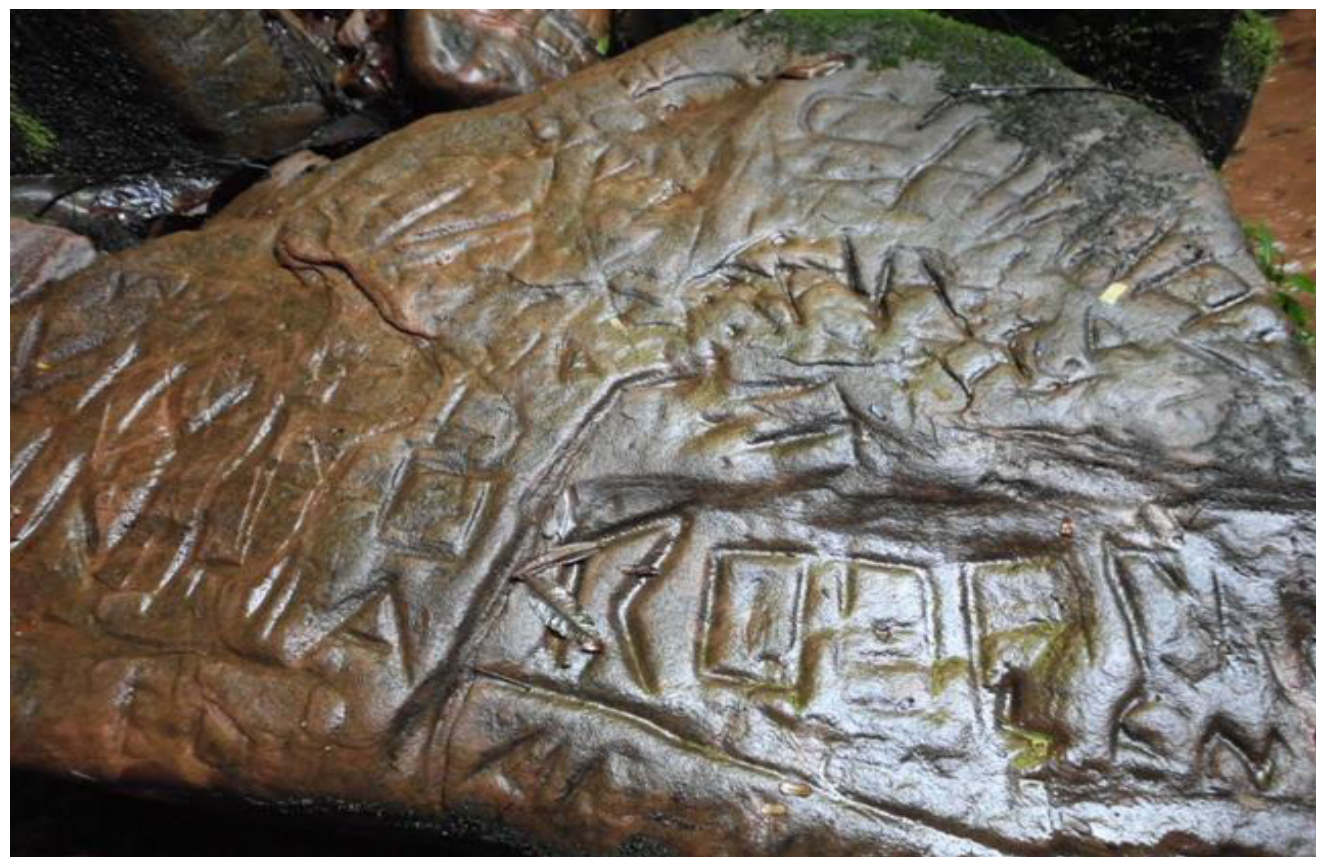

Figura 6: Marcas da degradação dos atrativos (geopatrimônio) no trajeto do roteiro ao Santuário de Pedra Caída.

Figure 6: Marks of degradation attractive (geopatrimony) in the path of the tour to Sanctuary Pedra Caída.

Fonte: Fernando Pãozinho. (Em 5 de maio de 2012). Source: Fernando Pãozinho (On May 5, 2012).

Ressalta-se, ainda, o desconhecimento do potencial geoturístico, o que não favorece a iniciativa de elaboração de roteiros temáticos e de investimento em materiais alternativos de divulgação deste novo segmento.

Da situação acima verificamos oportunidade para melhorias deste cenário em Pedra Caída. Considerando-se as características de seu geopatrimônio, identificamos a possibilidade do desenvolvimento do geoturismo a partir da criação de programas direcionados ao público-alvo, que envolve sensibilização, aliada a atividades de lazer e recreação já oferecidos. Como perspectiva de adaptação do Complexo de Pedra Caída, vislumbra-se também a chance de servir de locus inicial do trabalho de geoturismo e, consequentemente, o pioneirismo em informações para a criação do Geoparque da Chapada das Mesas, uma vez que o Estado do Maranhão, até o momento da pesquisa, não possui nenhum geoparque. 


\section{Sugestões de ações e atividades para a prática do geoturismo no Complexo de Pedra Caída}

Diante do estudo de viabilidade da implantação do geoturismo no Complexo de Pedra Caída como segmento capaz de agregar valor à geodiversidade local, propõem-se algumas ações de gestão e atividades práticas com características e padrões voltados para a atividade geoturística. Ademais, o espaço delimitado para estudo é uma etapa inicial de trabalho para a sensibilização do reconhecimento das oportunidades que tal segmento pode trazer como agente de conservação e promoção do destino turístico Chapada das Mesas como Polo pioneiro do trabalho com o geoturismo no Estado do Maranhão.

Como núcleos para desenvolver o geoturismo, os geoparques, complexos ou similares devem possuir uma estrutura composta por painéis interpretativos ao longo dos roteiros, identificando cada geossítio, guias de turismo com especialização específica, folhetos informativos acerca do local e dos atrativos bem como disseminar práticas de educação ambiental. Além disso, deve possuir centro de visitantes com capacidade adequada e dotado de um espaço para exposição e outras atividades lúdicocientíficas, com o objetivo de dar o suporte necessário ao visitante e realizar ações introdutórias acerca do geoturismo

Ao perceber as instalações do Complexo de Pedra Caída e todos os seus roteiros com atrativos que podem ser considerados de apelo geoturístico por suas características e especificidades de vegetação tipo cerrado, propõe-se as seguintes ações:

\section{Trilhas e Painéis Interpretativos}

Para que se promova a educação geo-ambiental e a boa prestação de serviço ao turista, deve-se primeiramente, segundo Nascimento, Ruchkys, Mantesso-Neto (2008), fazer uma boa relação entre os pontos de interpretação e assuntos de interesse geoturísticos. Por meio de estudo e entendimento específico, o condutor pode tornar o roteiro ainda mais interessante, explicando as especificidades da área e relacionando-a a atividades dinâmicas. Exemplos de assuntos que podem ser explorados na interpretação com foco no conhecimento do geopatrimônio ainda segundo os mesmos autores, são:

a) Solos, ciclo das rochas, tectonismo, falhas e fraturas, estratificação, evolução das variações do relevo ao longo das eras geológicas na região do Parque Nacional da Chapada das Mesas;

b) Processos erosivos; Organização das camadas de arenito nos monumentos e formações em Pedra Caída;

c) Feições do relevo; intemperismo químico e biológico; falha geológica; processo de formação dos cannyons; 
O geoturismo como segmento diferencial para o polo turístico da Chapada das Mesas: estudo de viabilidade de práticas geoturísticas no Complexo de Pedra Caída em Carolina (MA)

d) Evolução das vertentes, rupturas de nível e divisores de águas; granulometria dos sedimentos, características singulares da geodiversidade local.

Ao longo das trilhas interpretativas devem constar sinalizações informativas e painéis interpretativos dinâmicos, com dados e imagens variando entre mapas de localização e outros pontos de curiosidade disponíveis, produzidos para sensibilizar e educar acerca da degradação do patrimônio local, de modo a levar o visitante a se envolver nesta experiência de conhecimento e lazer.

Dessa forma, a cada geossítio, o condutor pode ter o auxílio do painel para que as informações sejam repassadas de forma satisfatória e o passeio torne-se mais temático, trazendo o geoturismo como segmento turístico de apreciação e valorização. As vantagens deste tipo de estratégia de interpretação são alcançadas graças ao modo de exposição acessível da informação, dando mais liberdade ao visitante em estabelecer seu próprio ritmo de passeio.

\section{Elaboração de folhetos, cartilhas e mapas de localização dos roteiros.}

A entrega de material informativo leva a uma estratégia capaz de tornar a sensibilização ainda mais interessante, porque o turista poderá ter em mãos um material de apoio para acompanhar durante os percursos da visitação. Esse material pode ser distribuído logo no inicio, quando do repasse de informações no salão de recepção. O material deve conter informações mais detalhadas sobre a geodiversidade do local, destacando o geopatrimônio e repassar dicas de orientações de geoconservação. Ele é, ainda, um recurso para o turista levar consigo informações relevantes que podem ser utilizadas como estratégia de marketing, na divulgação das atividades realizadas no Complexo de Pedra Caída.

Outras atividades e ações que podem ser desenvolvidas nas dependências do Complexo de Pedra Caída, que vão de exposições sobre a geodiversidade local à prática de esportes radicais. Também a realização de oficinas voltadas para a educação geoambiental, introduzindo princípios de sensibilização com crianças, permitem que escolas agendem passeios - o que fortalece ainda mais a associação da imagem ao produto geoturístico.

Para que a comunicação torne-se eficaz entre os turistas e o Complexo de Pedra Caída, seria interessante contar com uma loja ou centro de apoio ao visitante na cidade de Carolina (MA), em vista de que a maior parte dos visitantes se hospeda na sede do município. Logo a partir do centro de apoio, seria possível captar uma demanda mais segmentada e a venda de um voucher ou cartão para identificar os serviços a serem utilizados no Complexo de Pedra Caída. Deve-se pensar também na logística de transporte dos visitantes, para complementar ainda mais o leque de serviços oferecidos. O Complexo de Pedra Caída poderia oferecer o transporte da sede do município de Carolina até o próprio complexo. 


\section{Implantando um sistema de Gestão do Espaço}

Conforme o diagnóstico realizado, o contexto é favorável para a prática do geoturismo no Complexo de Pedra Caída. As iniciativas devem ser assumidas por diferentes atores. O proprietário e outros atores vão consolidando o capital social do território, que envolve o Complexo. As intervenções serão orientadas no sentido de fortalecer a prática do geoturismo no Complexo, e produzir efeitos multilaterais em cadeia em outros setores.

Com suas iniciativas e esforços, os atores locais podem contribuir significativamente para melhorar ou criar condições de desenvolvimento em três sistemas interdependentes: o econômico, o social e o ambiental. Assim, à medida em que as iniciativas e o relacionamento intersetorial se fazem de maneira articulada, a prática do geoturismo se fortalecerá produzindo efeitos em cadeia, visando, assim, o desenvolvimento territorial (integral e competitivo) do Complexo de Pedra Caída para o Pólo Chapada das Mesas.

A Gestão integrada no Geoturismo alia-se ao planejamento sustentável, possibilitando que o visitante, ou geoturista, possa consumir um produto econômico que traga resultados satisfatórios, como a preservação e conservação do espaço e a inclusão da comunidade. Em pesquisa, constatamos como ações os cursos de monitores ambientais ofertados pelo IBAMA e SEBRAE e a presença do Instituto Chico Mendes para a Conservação da Biodiversidade, que realiza inspeção nos atrativos, pois o Complexo está localizado na Zona de Amortecimento do Parque Nacional da Chapada das Mesas.

Mesmo contando com um acompanhamento na manutenção dos atrativos, por parte do Instituto Chico Mendes, e a capacitação de guias condutores, os impactos negativos são visíveis. Assim como o trabalho e a preocupação que têm os guias em limpar os atrativos todos os dias. Devido à fragilidade do seu patrimônio geológico, independente de se implantar a prática do geoturismo no local, necessita-se desenvolver um controle de conservação, uma vez que muitos visitantes acabam interferindo nas formações rochosas, influenciando na degradação de tais cenários. Portanto, sugerimos a ferramenta de gestão EDIL - Educação, Infraestrutura e Liderança, elaborada por Héctor Sanin Ángel - Consultor ILPES. Essa ferramenta tem por objetivo proporcionar experiências qualificáveis e bem sucedidas a partir da gestão sinérgica dos três componentes: educação cidadã, condições físicas e controle, para garantir o adequado uso do equipamento público.

Um programa de educação dos usuários instrui os visitantes sobre a importância de fazer bom uso do espaço, da paisagem das instalações durante os passeios. Este programa pode ser feito com brigadas juvenis, com recreação pedagógica dirigida a grupos, com lemas e avisos que estimulem à preservação. E para que os esforços de educação obtenham resultados positivos, são necessárias condições adequadas de infraestrutura, como criar as condições físicas e operativas com a finalidade de que os usuários aceitem, sem desconforto, as medidas de conservação, como recipientes para 
O geoturismo como segmento diferencial para o polo turístico da Chapada das Mesas: estudo de viabilidade de práticas geoturísticas no Complexo de Pedra Caída em Carolina (MA)

jogar o lixo em disposição adequada, boa sinalização, criação de um ambiente funcional e estético, e boa manutenção. Apoiadas em condições adequadas de infraestrutura, as ações educativas vêm proporcionar o comportamento desejado dos usuários. Assim, o controle deve ser exercido com advertências, pelos guardas do parque e com medidas de punição formadora aos infratores das normas de conduta e de preservação do ambiente.

O "EDIL" é uma ferramenta de gestão que funciona com a articulação integral do tripé - educação, infraestrutura e liderança - como visualizamos na figura abaixo. É necessário sinergia para o perfeito funcionamento de tal estrutura.

EDIL

Um enfoque para fazer cidade $\odot$

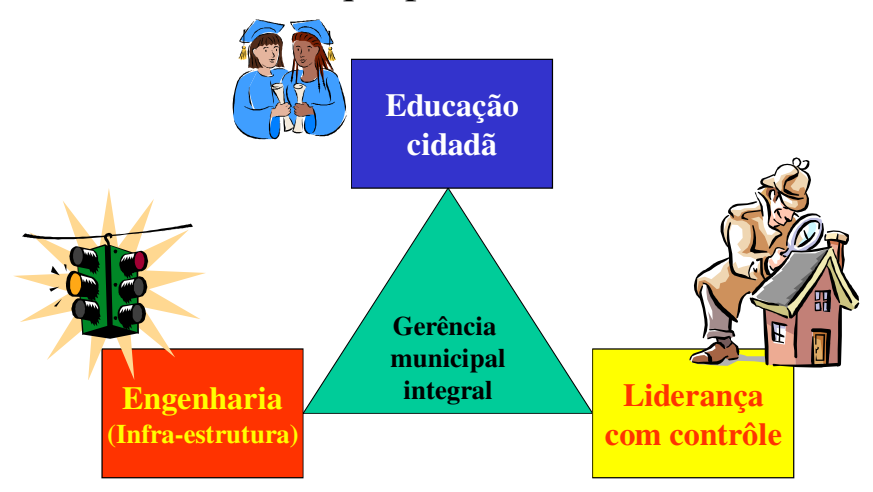

Figura 7: tripé do Sistema EDIL.

Figure 7: tripod of EDIL System.

Fonte: Héctor Sanin Angel, Consultor ILPES (2007).

Source: Héctor Sanin Ángel, Consultor ILPES (2007)

Com essa ferramenta de gestão é possível evitar a entropia, ou seja, os impactos negativos que a presença de visitantes pode causar no espaço e no patrimônio geológico do Complexo de Pedra Caida.

\section{Considerações Finais}

As concepções trabalhadas nesta pesquisa deram ênfase à geoconservação, a partir do segmento do geoturismo como principal meio de transmissão desta sensibilização acerca do reconhecimento e valorização do geopatrimônio.

Conclui-se com a pesquisa a viabilidade da prática do geoturismo no Complexo de Pedra Caída em Carolina - MA, diante das características de sua geodiversidade. Observa-se, ainda, que a formatação deste segmento necessita de um planejamento 
Lima, R.N.; Câmara, R.J.B.; Pãozinho, F.C.

turístico que vise aos padrões de elaboração de roteiros e criação de estruturas voltadas para o geoturismo. E, assim, o Complexo de Pedra Caída, localizado na Zona de Amortecimento do Polo Turístico da Chapada das Mesas, ser o pioneiro no desenvolvimento deste segmento no Maranhão. O estudo propõe melhorias nos roteiros e sugere a implantação de uma ferramenta de gestão para garantir a preservação do patrimônio geológico do Complexo.

Diante da viabilidade da prática do geoturismo no Complexo de Pedra Caída, acredita-se na possibilidade de estudos visando propor para o Parque Nacional da Chapada das Mesas, a criação de um geoparque, uma vez que no Estado do Maranhão não existe qualquer geoparque. Nessa perspectiva será natural o surgimento de nichos de mercado, modificando a cadeia de negócio para sustentar esse novo segmento, o geoturismo.

Essas ações podem subsidiar pesquisas mais amplas, que envolvam todo o território do Parque Nacional da Chapada das Mesas, relacionando aspectos da geografia em geral com a atividade turística, demonstrando a geodiversidade através de práticas sustentáveis.

\section{Referências bibliográficas}

ALMEIDA, R.A. Geografia e cartografia para o turismo. ed. rev. e ampl. São Paulo: IPSIS, 2007.

BRASIL. Presidência da República. Decreto de 31 de janeiro de 2006. Altera o art. 10 do Decreto de 12 de dezembro de 2005, que cria o Parque Nacional da Chapada das Mesas, nos Municípios de Carolina, Riachão e Estreito, no Estado do Maranhão.BrasíliaDF,2006.Disponível em: <http://www.planalto.gov.br/ccivil 03/ Ato2004-2006/2006/Dnn/ Dnn10759.htm>. Acesso em: 16 maio 2012.

CHAPADA das mesas... Revista roteiros do Maranhão, ano 1, n. 1., p. 8-9, nov. 2009a.

FUNDAÇÃO SOS Chapada do Araripe... [S.I.: s.n.], 2012.

Disponível em: <http://verdejandonoradio.blogspot.com.br/2010/05/fundacao-sos-chapadado-araripe-recebe.html>. Acesso em 15 maio 2012.

INSTITUTO BRASILEIRO DO MEIO AMBIENTE E DOS RECURSOS NATURAIS RENOVÁVEIS. Relatório técnico do sobrevôo na área abrangida pelo Parque Nacional da Chapada das Mesas e entorno. [S.I.]: IBAMA. 2005.

LIRA, I. S. Metodologia para a elaboração estratégias de desenvolvimento local. Coletânea de transparências do curso "Curso Internacional de Gestão Estratégica do Desenvolvimento Regional e Local". Brasília, 2009.

SANÍN, H. Coletânea de transparências do curso "MBA - CEPAL Gestão de Projetos para Desenvolvimento de APLs". Brasília, 2007.

PÃOZINHO, F.C. O geoturismo como segmento diferencial para o polo turístico da chapada das mesas: estudo de viabilidade de práticas geoturísticas no Complexo de Pedra caída em Carolina-MA. 2012. 121 f. Monografia - Universidade Federal do Maranhão, 2012. 
O geoturismo como segmento diferencial para o polo turístico da Chapada das Mesas: estudo de viabilidade de práticas geoturísticas no Complexo de Pedra Caída em Carolina (MA)

NASCIMENTO, M. A. L., RUCHKYS, U. A., MANTESSO-NETO, V. Geodiversidade, Geoconservação e Geoturismo: trinômio importante para a proteção do patrimônio geológico. Natal: Central Zila Mamede, 2008.

NASCIMENTO, M. A. L.; RUCHKYS, U. A.; MANTESSO-NETO, V. Geoturismo: um novo segmento do Turismo. Revista de Turismo. v. 2., n. 3. dez, 2007. Disponível em:http:// www.redeapasul.com.br/quadrilatero ferrifero/

Geoturismo Um Novo Segmento do Turismo.pdf>. Acesso em: 26 fev. 2012.

RUCHKYS, Úrsula de Azevedo. Patrimônio geológico e geoconservação no quadrilátero ferrífero, Minas Gerais: potencial para a criação de um geoparque da UNESCO. 2007. f. Tese (Doutorado em Geologia)-, Instituto de Geociências da UFMG, 2007. Disponível em: $<$ http://www.bibliotecadigital.ufmg.br/dspace/bitstream/1843/MPBB-76LHEJ/1/ tese ursula ruchkys.pdf >. Acesso em 14 fev. 2012.

SERVIÇO BRASILEIRO DE APOIO ÀS MICRO E PESQUENAS EMPRESAS. Estudo de capacidade de carga turística do destino de Carolina. [S.I.]: SEBRAE [2009?].

Rozuila Neves Lima: Universidade Federal do Maranhão, São Luis, MA, Brasil.

Email: rozuila@hotmail.com

Link para o currículo Lattes: http://lattes.cnpq.br/4654403359646517

Rosélis de Jesus Barbosa Câmara: Instituto Universidade Federal do Maranhão, São Luis, MA, Brasil.

Email: zelis.camara@yahoo.com.br

Link para o currículo Lattes: http://lattes.cnpq.br/1995690638678298

Fernando Campelo Pãozinho: SEBRAE, São Luis, MA, Brasil.

Email: nando.camp@hotmail.com

Link para o currículo Lattes: http://lattes.cnpq.br/1676558237174208

Data de submissão: 30 de junho de 2013

Data de recebimento de correções: 30 de junho de 2013

Data do aceite: 01 de setembro de 2013

Avaliado anonimamente 